\title{
Factors associated with round-trip carsharing frequency and driving-mileage impacts in London
}

This is an accepted manuscript of an article published in the International Journal of Sustainable Transportation, available online at: https://doi.org/10.1080/15568318.2018.1538401

\section{Citation:}

Wu, C., Le Vine, S., Clark, M., Gifford, K., Polak, J. (2019) Factors associated with round-trip carsharing frequency and driving-mileage impacts in London. International Journal of Sustainable Transportation.

\author{
Chenyang Wu ${ }^{a}$, Scott Le Vine ${ }^{a, 1}$, Matthew Clark $^{\mathrm{b}}$, Kate Gifford ${ }^{\mathrm{c}}$, and John Polak \\ a Imperial College London, UK \\ b Steer Davies Gleave, London, UK \\ ${ }^{c}$ Carplus/Bikeplus, Leeds, UK
}

${ }^{1}$ Corresponding author: slevine@imperial.ac.uk 


\begin{abstract}
This study draws on respondents from Greater London within the 2016/17 wave $(n=2,640)$ of Britain's Annual Survey of carsharing users, which we enrich with external data from the 2011 England and Wales Census and small-area income estimates. Focusing on round-trip carsharing users, we present multivariate analyses of frequency-of-usage of carsharing vehicles and impacts on annual vehicle miles travelled (VMT). Published attribute effects from other geographic and contextual circumstances are compiled and compared (where direct comparison is possible) with the specific attribute effects that we report in this paper. We demonstrate a statistically significant link between customer satisfaction with proximity of carsharing vehicles and VMT impacts. Car ownership (both current, and changes upon joining a carsharing service) is shown to have intuitive structural impacts. We find that frequent usage is associated ceteris paribus with increasing VMT after joining a carsharing service, and that subscribing to multiple types of carsharing is associated with frequent carsharing usage and a reduction in VMT. Interestingly, we did not find any significant effect of household income on either frequency-of-usage or VMT impacts.
\end{abstract}

Keywords: Carsharing, Travel behaviour, Frequency of usage, Vehicle miles travelled 


\section{Introduction}

Carsharing (termed "car clubs" in the UK vernacular) is a form of shared-mobility in which a user accesses a vehicle to use for a relatively brief period (shorter on average than car rental; typically in units of minutes/hours rather than days). There are estimated to be 1.4 million members of such services in the US (Roberts, 2017) and 245,000 in the UK, with $79 \%$ of the UK total $(193,500)$ based in Greater London (Carplus, 2017).

The expansion of shared mobility has in many cities taken place alongside supportive public policy, notably the provision of priority access to on-street parking. There is therefore a public interest in developing the evidence base regarding user behaviour, in order to maximise the public benefit. Due to this need, these research questions have attracted increasing focus form the transport research community (discussed in detail in Section 2).

The body of literature on the impact of carsharing has studied various aspects, including car ownership levels (Martin, Shaheen and Lidicker, 2010; Giesel and Nobis, 2016; Namazu and Dowlatabadi, 2018), impacts on vehicle miles travelled (VMT) (Cervero, 2003; Cervero and Tsai, 2003; Cervero, Golub and Nee, 2007), usage of alternative modes of transport (Martin and Shaheen, 2011b; Wang, MacKenzie and Cui, 2017), and environmental impacts such as pollutant emissions (Firnkorn and Müller, 2011; Martin and Shaheen, 2011a; Chen and Kockelman, 2015). Usage pattern of carsharing members have also received attention, including Niels and Bogenberger (2017), Morency et al. (2011) and Habib et al. (2012).

This study focuses on the usage and impact of round-trip carsharing in Greater London as of 2016. London presents an interesting policy context, as strategic transport policy is the responsibility of London's regional government, with direct responsibility for managing much of the street network held at the subregional municipal ("borough") level of government. Due to the importance of on-street parking to carsharing services, each of London's 33 boroughs therefore has great influence in determining which services operate within their boundaries and under which terms and conditions. 
We employ data from Britain's Annual Survey of carsharing users. Results from the Annual Survey are traditionally (since inception in 2007) employed to track the growth and impacts (driving mileage, car ownership, emissions, etc) of carsharing activity. Documenting such impacts is important as many carsharing vehicles are stored on-street with the explicit permission of the relevant borough, and this permission depends in some cases on demonstrating that carsharing activity contributes to achieving the borough's goals for the transport sector. Therefore, the primary focus of the published results from the Annual Survey is to document system-wide effects, reported as a consistent time series in each edition of the Annual Survey.

Though not traditionally employed for purposes of identifying factors associated with carsharing user behaviour, the Annual Survey data are suitable for such purposes. The motivation for the present research is therefore to extend the usual descriptive statistical analyses via multivariate analyses of the survey's microdata (to allow identification of ceteris paribus effects) focusing on two of the principal dimensions of carsharing user activity: Frequency-of-usage and Impact of carsharing subscription on users' annual driving mileage.

The remainder of this paper is organised as follows: Section 2 synthesises the relevant background literature, and Section 3 introduces the individual analyses, with Section 4 concluding the paper.

\section{Background}

In the presentation of results (Section 4), we compare parameter effects that we obtained in this study with analogous effects from the literature. This discussion of the relevant background is therefore oriented around the two statistical analyses that we performed:

Section 2.1 discusses prior studies of carsharing users' frequency of using the services, and Section 2.2 reviews studies on the carsharing impact of users' vehicle miles travelled. 


\subsection{Frequency of usage}

One important stream of carsharing research addresses how the frequency-of-carsharingusage is influenced by the characteristics of users, the type of carsharing, the existence of other modes of transport, and the land-use. This is an important dimension of carsharing user behaviour, as the number of users (which is widely quoted; see the $1^{\text {st }}$ paragraph of the Introduction) and their frequency of usage combine to yield aggregate carsharing usage.

Table 1 summarises the body of literature that has investigated frequency of carsharing usage. Table 2 consists of only studies that have employed multivariate regression techniques, and which therefore reported parameter effects that are amenable to comparison with our results (presented in Section 4).

Table 2 presents studies that modelled either (or both) round-trip carsharing (in which a vehicle must be returned to its starting point) and one-way carsharing services (in which a vehicle may be returned anywhere within a designated operating zone), with common variables as columns. Age, population density, density of businesses, and public transport access are the explanators considered most frequently by researchers. In general, users who are younger and living in areas with higher density of users tend to use carsharing more frequently, and vise versa for high income users. The effects of other parameters are mixed, and the literature does not provide any clear guidance regarding different influences on usage frequency of round-trip versus one-way carsharing.

Another set of studies (shown only in Table 1, rather than also in Table 2) has investigated patterns of variation amongst carsharing users. Examples here include Morency et al. (2011), in which operational data allowed for examination of the repetitiveness of usage patterns over the length of a user's membership. The authors indicate that a large share of carsharing members used the service on an infrequent basis. Two other studies from China shown in Table 1 also employed clustering techniques to identify segments of carsharing users defined by usage patterns (Hui, Ding, Zheng, et al., 2017; Hui, Wang, et al., 2017). 
Four of the studies shown in Table 2 analysed round-trip (as opposed to one-way) carsharing. Costain et al. (2012) found that the typical member makes fewer than 30 trips per year via carsharing, with a low male-female ratio and living in a lower median income household associated with higher frequency of carsharing usage. Habib et al. (2012) found the opposite effect for gender, and that younger members were more frequent users. Kang et al. (2016) found a similar result with respect to age, and de Lorimier and El-Geneidy (2011) found a consistent result as Costain et al. (2012) with respect to household income.

\subsection{Impacts on driving mileage}

The body of literature on the impact of carsharing on users' vehicles miles travelled (VMT) generally finds that users experience on average a decrease in VMT, though the aggregate effect masks wide variation. Martin and Shaheen (2011), for instance, demonstrate that the majority of users increase their VMT but by a small amount, and this is outweighed by the minority who decrease their VMT and do so by a larger average magnitude.

Much of the VMT-impacts literature consists of relatively early studies, and employ simple descriptive statistics rather than multivariate regression approaches (see Table 3). Several studies (Cervero et al., 2007; Costain et al., 2012) however have employed regression techniques to relate change in driving mileage with user characterstics; these are summarised in Table 4.

Consistent with Martin and Shaheen (2011), earlier longitudinal studies by Cervero and colleagues Cervero et al. (Cervero, 2003; Cervero and Tsai, 2003; Cervero et al., 2007) also indicate that the impact of VMT is non-linear. Cervero reported that carsharing users (in the San Francisco Bay area) tended to increase their VMT early in their carsharing membership, and then tended to switch to a net reduction of VMT in the longer term. The largest reduction of carsharing users' VMT was found to ocur in the first year of becoming a carsharing member, and forgoing their current private vehicles or a planned car purchase are major explanatords for individuals reducing their VMT. 
It is worth noting the extent of diversity in the types of data that researchers have employed to analyse these research questions. As noted previously, studies such as Morency et al (2011) have employed operational data from a carsharing service, in which each user's recorded usage over a long period (including date, time, duration, location, etc. of each usage episode) can be correlated with their characteristics. A more common type of data is user surveys; examples include Becker et al. (2017), Martin and Shaheen (2011), and the series of studies by Cervero and colleagues. The latter type of approach (which was taken for the present study, as described in the next section) is limited by considerations of sampling errors and biases, and recording of carsharing usage with much less information than the usage-episode-specific information that is in principle available through operational datasets. Operational datasets have limitations as well, however, including limited demographic details and a lack of information about journey characteristics such as purpose and whether the journey involved transpoarting any large items (luggage, etc.). Operational datasets also do not generally capture information on carsharing members' usage of other forms of transport, and their travel behaviour prior to joining the carsharing service, which is needed to perform analysis of VMT impacts.

\section{Data}

An Annual Survey of carsharing users in the UK has been undertaken each year since 2007 (Carplus, 2017). The data employed for this study are sourced from the tenth edition, with field data collection during Autumn 2016. The survey was administered via a CASI protocol, with all 'active' carsharing subscribers invited to participate via email by the operator of the service to which they subscribe (the definition of an active member is made individually by each operator).

The response rate within Greater London was 2\% (4,023 / 193,500); single-digit response rates are not uncommon in bespoke surveys of shared-mobility users, and in the case of this specific survey the low response rate could be linked to the decentralised definition of 
'active' with some carsharing operators applying looser criteria than others. The UK's National Travel Survey (Lepanjuuri et al., 2017) and the US's National Household Travel Survey (NHTS, 2016) (as well as various regional travel surveys in each of these countries) have both begun collecting data on shared-mobility in recent years, which will in due course provide the opportunity to evaluate whether (and in which ways) the Annual Survey's data are or are not statistically representative.

The Annual Survey contains an "operator survey" completed by each carsharing operator directly, as well as the "member survey"; the latter is the data employed in this research. The operator survey contains data such as the emissions-classification of their vehicle fleet.

After removing participants surveyed by one-way carsharing operators and respondents with incomplete data, the database used for analysis in this research consists of 2,640 respondents living in Greater London. The Annual Survey data contains the following data points used in this research²:

- The year of joining carsharing

- The membership of other types of carsharing

- The time, purpose, and number of adults and children travelled with in the last carsharing trip

- The alternative mode if there was no carsharing in the last carsharing trip

- Carried large item or not in the last carsharing trip

- The reason for using carsharing in the last carsharing trip

- The frequency of using different modes of transport including carsharing

- Car ownership before and after joining carsharing

- The vehicle miles travelled change after joining carsharing

${ }^{2}$ The survey questionnaire is accessible via (Carplus, 2017). 
- Satisfaction of the proximity, availability, and quality and condition of the carsharing vehicles

Variables employed in this study are summarised in Table 5, along with descriptive statistics (mean and standard deviation). A correlation matrix of the variables is available from the authors on request.

Due to the focus of the Annual Survey on system-wide monitoring rather than the userspecific determinants of carsharing activity, demographic characteristics of respondents and the spatial context of their residence are notable omissions. The Annual Survey dataset contains the full residential postcode ${ }^{3}$ of each respondent, which we drew on to enrich it with external data. The external data were average household income (London Datastore, 2015) and the following variables from the most recent England and Wales Census (Office for National Statistics, 2011b, 2011a, 2011c), all joined to the Annual Survey data at the "LowerLayer Super Output Area" geographic unit (average population 1,500):

- Level of education (expressed as percentage of adults with bachelor's or higher degree

- Household composition (expressed as percentage of households having at least one child under age 16)

- Population density (persons per hectare)

- Housing tenure (expressed as percentage of households that own their dwelling unit)

\section{Numerical analysis}

The analyses consisted of two sets of linear regression models (self-reported frequency of usage and impact-of-carsharing subscription on annual VMT). The remainder of this section

\footnotetext{
${ }^{3}$ UK postcodes are much smaller than US zip codes; each residential UK postcode covers $\sim 15$ dwelling units.
} 
presents these two analyses in turn. We note that the parameter estimates do not indicate causality, therefore our speculation in this section (and the Conclusions section which follows) regarding possible interpretations employs conditional language ('may', 'could', 'suggests', etc.) and should be viewed as informed guesswork rather than demonstration of causality.

\subsection{Frequency of usage}

Frequency of carsharing usage was collected via a five-point scale (3+ times/week, 1-2 times/week, At least once per month, At least once per year, Never), with user responses converted into usage episodes per year via the midpoint of each category (the $3+$ times/week category which does not have a midpoint was converted at the rate of 3 uses/week $=156$ uses/year) .

Table 6 contains the results from the analysis of frequency of usage. We report two sets of parameters: Model \#1a includes all parameters, and Model \#1b is a reduced-form model of only parameters with p-values less than 0.15 (i.e. highly-insignificant parameters are excluded).

Model \#1b demonstrates that being a newer user (i.e. having joined recently) is associated with frequent usage of the carsharing service, which may suggest that longer-term users' needs for car-based mobility tend to reduce over time. Having an additional subscription to a one-way carsharing also positively associated with the frequency of using round-trip carsharing, which suggests that the presence of the newer one-way form of carsharing is complementary (rather than a substitute) to how frequently subscribers use round-trip carsharing. This is somewhat different than the findings of Becker et al. (2017), who report that membership in a round-trip carsharing system has a negative effect on the frequency of one-way carsharing usage.

Having carried heavy luggage during the most recent carsharing usage was negatively associated with frequency-of-usage, which may reflect that this type of travel need is 
relatively infrequent, and other non-carsharing modes are typically used by subscribers who use carsharing for this type of journey. Having shed a private car upon joining carsharing is positively linked with frequency-of-usage, perhaps indicating that such users have latent high demand for automobility which manifests as frequent carsharing usage. Current ownership of a car is, however, strongly negatively linked with frequency-of-carsharing-usage. This is intuitive, as carsharing usage fees are generally charged at average cost (which must include a component for recovery of fixed capital costs) whereas car owners only face [lower] marginal costs when using a private household car. For carsharing members that own a car, circumstances that may serve as motivators for acquiring their carsharing membership could be the unavailability of their household vehicle at specific times, or their desire to use carsharing as a 'last-mile' mode of travel as part of a multimodal journey employing public transport for the longest leg of the journey, or as a form of "mobility insurance" in case their personal car becomes out of service unexpectedly.

A user indicating that their most recent carsharing journey would have been made by bicycle or walking if carsharing were unavailable is another factor that we found to be positively linked with the frequency of usage. We do not have a clear interpretation for this result; it suggests that for at least some carsharing journeys the nearest substitute modes of transport are walking or cycling.

We found a positive link between shared-vehicle occupancy and frequency-of-usage, which is consistent with (Cervero and Tsai, 2003). This effect is statistically significant for both adults and children as car ocupants, with a larger magnitude for children. The journey purposes most strongly associated with frequency-of-usage are Commuting and travel-toEducation, with Personal Business and Leisure comparatively weakly linked with frequent usage.

The bottom row of Table 2 compares our results to common correlates of carsharing frequency-of-usage reported in the literature. The only directly comparable effect for which 
we report a statistically significant effect is the effect of car ownership; our negative effect is consistent with the finding of Müller et al. (2017) (which was in the context of free-floating carsharing), but the opposite sign of the results found by Becker et al. (2017).

\subsection{Impacts on annual driving mileage}

Table 7 presents the regression results of the impact of round-trip carsharing subscription on each user's annual VMT (including all cars whether owned privately, rented, accessed from the carsharing operator or a family member, etc.). Consistent with earlier literature (e.g. (Martin and Shaheen, 2011a)), the UK's Annual Survey has consistently over time found that there is a net negative impact (i.e. reduction) on annual VMT (570 miles/person/year in 2016/17 in London), which arises from a small proportion of users decreasing their VMT each by a large amount, and a larger proportion increasing their VMT but by a much smaller amount.

The results shown in Table 7 arise from a simple transformation of the VMT impacts, in which we capped the impacts at $+5,000$ miles/yr (for increases) and $-5,000$ miles/yr (for decreases). We retain the small number of people $(n=70)$ with VMT impacts larger than $+/$ 5,000 miles in the analysis; we simply recoded their VMT impact to the capped value. This reduction in the impact of outliers in the data improves goodness-of-fit from an adjusted $r^{2}$ of 0.10 to 0.17 . All parameter effects retain their sign; results from the 'uncapped' regressions are available from the authors on request.

Table 7 shows that fewer variables in this analysis are statistically significant, compared to the analysis of frequency of carsharing usage (Table 6). We find that being a member of both round-trip and one-way carsharing is associated with having reduced one's annual VMT. The only statistically significant effect (negative) due to journey purpose of most recent carsharing activity is for the Visiting Friends/Relatives purpose. We do not have a hypothesis for this result pertaining to this journey purpose; further research will be needed to determine whether this result is robust across different contexts, and if so why it is found. Carrying 
heavy luggage on one's most recent carsharing journey was positively associated with VMT impacts; this suggests that such journeys might have otherwise been performed by nondriving forms of travel. How frequently one uses a taxi was found to be positively linked with frequency of usage (Table 6), but negatively linked with VMT impacts. This could indicate that taxi usage and carsharing usage are complementary and taken together serve as a combined substitute for private car travel. Also, as would be expected, having decreased one's private car ownership upon subscribing to a carsharing is very strongly linked with also decreasing one's annual VMT.

Finally, the level-of-satisfaction of carsharing subscribers with the proximity of the carsharing vehicles to their home is associated with VMT reductions, which suggests that a greater density of carsharing vehicles may be linked with larger VMT reductions.

In comparison to previously published regression analyses of VMT impacts (Table 4), the effects that we report are neither strictly consistent nor strictly inconsistent with the existing published literature, because either our results or those in the literature (or both) are statistically insignificant for effects which are common across studies.

\section{Conclusions}

In order to analyse how carsharing users in London use the service and its impact of on their car usage, we performed multivariate analysis of the 2016/17 wave of Britain's Annual Survey of carsharing users, focusing on residents of Greater London that are subscribers of round-trip carsharing. The regression analyses that we undertook of frequency of carsharing usage and impacts on annual VMT allow ceteris paribus attribute effects to be estimated. We then compare the effects we obtained for London in 2016 with results from prior studies in other contexts.

Our results build on those of earlier studies in several notable ways. In some instances Britain's data resources allow us to identify effects that are intuitive but not previously 
reported in the literature, such as using carsharing to transport bulky items ("luggage") being associated with infrequent carsharing usage. We also find that, rather intuitively, using carsharing for Commuting and Travel-to-Education are more strongly associated with frequency-of-carsharing than other trip purposes (e.g. Leisure and conducting Personal Business). In other instances we find results that diverge from earlier literature, for instance with regard to the effect of car ownership on usage frequency of round-trip carsharing. The only earlier study to report such an effect (Kang et al. 2016) found car ownership to be positively associated with carsharing usage frequency; we report the opposite. One possibility is that this divergence with previously published results reflects that the causal mechanisms underpinning the effect are context-dependent, such as varying with differences in the cost structures of private car ownership and public policies towards automobility. Further accumulation of empirical results will be needed to answer this question.

With regard to impacts on driving mileage upon joining round-trip carsharing, we find that the trip purpose most significantly associated with a decrease in VMT is use of carsharing to Visit Friends/Relatives. It may be that these journeys tend to take place at times and in places where public transport is less competitive than, for instance, traditional commuting patterns. This result may therefore indicate that carsharing members that use the service for Visiting Friends/Relatives have reduced their driving mileage by switching from driving for other types of journeys where non-car forms of transport are more competitive.

Interestingly, we found that income, traditionally one of the strongest predictors of travel behaviour, was not significantly associated with either carsharing usage frequency or driving mileage impacts. There is evidence of income decreasing in recent years in its salience as an explanator of driving behaviour, with car use declining most sharply for higher income groups (see, e.g., Fig. 14 in Goodwin (2012)). Other studies have found that income is negatively associated with usage frequency of carsharing (Costain et al. 2012; de Lorimer and El-Geneidy, 2013) and linked with positive (i.e. increasing) VMT impacts upon joining a 
carsharing service. One possibility is that the data fusion approach that we employed to impute an income level to each survey respondent based on average income of their neighbourhood could cause our approach to fail to detect a 'true' but weak income effect. Further research will be needed to either provide further support for these earlier findings or for the lack-of-significant effect that we found in the present study.

We were able to link between users self-reported satisfaction with various aspects of their carsharing service and frequency-of-usage/VMT-impacts. The only statistically significant relationship that we found is with respect to the proximity of the service's vehicles to one's home: we found that higher satisfaction with the proximity of vehicles is associated with larger declines in driving mileage. This suggests that monitoring and ensuring high levels of vehicle availability within carsharing service areas may be a sensible strategy to encourage reductions in VMT.

It is hoped that further findings will emerge in the near future to either confirm or contrast with the results that we present here, and that the results we present in this study will be useful to future researchers as well as both practitioners in the carsharing industry and public sector staff that set policies relating to carsharing.

\section{Acknowledgements}

The authors thank the two anonymous referees for helpful feedback on an earlier version of this manuscript, however any remaining errors are the authors' sole responsibility.

Author contributions are as follows: KG directs the Annual Survey, and MC oversees the fieldwork and data-compilation/processing. CW, SL and JP designed this study's research plan. CW performed the numerical analysis; CW and SL drafted the manuscript. This study was not externally funded. 


\section{References}

Becker, H., Ciari, F. and Axhausen, K. (2017) 'Comparing car-sharing schemes in Switzerland: User groups and usage patterns', Transportation Research Part A: Policy and Practice, 97, pp. 17-29. doi: 10.1016/j.tra.2017.01.004.

Carplus (2017) Carplus annual survey of car clubs 2016-17: London.

Cervero, R. (2003) ‘City CarShare: First-Year Travel Demand Impacts', Transportation Research Record: Journal of the Transportation Research Board, 1839(1), pp. 159-166. doi: 10.3141/1839-18.

Cervero, R., Golub, A. and Nee, B. (2007) ‘San Francisco City CarShare: Longer-term travel-demand and car ownership impacts', Transportation Research Record: Journal of the Transportation Research Board, 1992, pp. 70-80. Available at: http://www.econstor.eu/handle/10419/59415.

Cervero, R. and Tsai, Y. (2003) 'San Francisco City CarShare: Second-Year Travel Demand and Car Ownership Impacts', Transportation Research Board 2004 Annual Meeting, 4683(November 2003). Available at: http://www.communauto.net/images/TRB2004002025.pdf.

Chen, T. D. and Kockelman, K. (2015) ‘Carsharing's life-cycle impacts on energy use and greenhouse gas emissions', in The 94th Annual Meeting of the Transportation Research Board,. Washington D.C: Transportation Research Record.

Costain, C., Ardron, C. and Habib, K. (2012) 'Synopsis of users' behaviour of a carsharing program: A case study in Toronto', Transportation Research Part A: Policy and Practice. Elsevier Ltd, 46(3), pp. 421-434. doi: 10.1016/j.tra.2011.11.005.

Firnkorn, J. and Müller, M. (2011) 'What will be the environmental effects of new free-floating car-sharing systems? The case of car2go in Ulm', Ecological Economics. Elsevier B.V., 70(8), pp. 1519-1528. doi: 10.1016/j.ecolecon.2011.03.014. 
Giesel, F. and Nobis, C. (2016) 'The Impact of Carsharing on Car Ownership in German Cities', Transportation Research Procedia. The Author(s), 19(June), pp. 215-224. doi: 10.1016/j.trpro.2016.12.082.

Goodwin, P. (2012) 'Peak Travel, Peak Car, and the Future of Mobility’, International Transport Forum Working Paper \#13. Available at: https://www.itfoecd.org/sites/default/files/docs/dp201213.pdf.

Habib, K. et al. (2012) 'Modelling users' behaviour of a carsharing program: Application of a joint hazard and zero inflated dynamic ordered probability model', Transportation Research Part A: Policy and Practice. Elsevier Ltd, 46(2), pp. 241-254. doi: 10.1016/j.tra.2011.09.019. Hui, Y., Wang, W., et al. (2017) 'Behavior Patterns of Long-term Car-sharing Users in China', Transportation Research Procedia. Elsevier B.V., 25, pp. 4666-4682. doi: 10.1016/j.trpro.2017.05.303.

Hui, Y., Ding, M., Qian, C., et al. (2017) 'Research on the operational characteristics of car sharing service stations: A case study of a car sharing program in Hangzhou*, Transportation Research Procedia. Elsevier B.V., 25, pp. 4144-4160. doi: 10.1016/j.trpro.2017.05.352.

Hui, Y., Ding, M., Zheng, K., et al. (2017) 'Research on Trip Chain Characteristics of RoundTrip Carsharing Users in China: Case Study in Hangzhou City', The 96th Annual Meeting of the Transportation Research Board, 9(6), pp. 1-19. doi: 10.3390/su9060949.

Kang, J., Hwang, K. and Park, S. (2016) 'Finding Factors that Influence Carsharing Usage: Case Study in Seoul', Sustainability, 8(8), p. 709. doi: 10.3390/su8080709.

Lepanjuuri, K. et al. (2017) National Travel Survey 2016 Technical Report. London Datastore (2015) GLA household income estimates for small areas. de Lorimier, A. and El-Geneidy, A. (2011) 'Understanding the factors affecting vehicle usage 
and availability in carsharing networks: A case study of Communauto carsharing system from Montréal, Canada', in 90th TRB annual meeting.

de Lorimier, A. and El-Geneidy, A. (2013) 'Understanding the Factors Affecting Vehicle Usage and Availability in Carsharing Networks: A Case Study of Communauto Carsharing System from Montréal, Canada', International Journal of Sustainable Transportation, 7(1), pp. 35-51. doi: 10.1080/15568318.2012.660104.

Martin, E. and Shaheen, S. (2011a) 'Greenhouse gas emissions impacts of carsharing in North America', IEEE Transactions on Intelligent Transportation Systems, 12(4), pp. 10741086.

Martin, E. and Shaheen, S. (2011b) 'The impact of carsharing on public transit and nonmotorized travel: An exploration of North American carsharing survey data', Energies, 4(11), pp. 2094-2114. doi: 10.3390/en4112094.

Martin, E. and Shaheen, S. (2016) 'Impacts of car2go on Vehicle Ownership, Modal Shift, Vehicle Miles Traveled, and Greenhouse Gas Emissions: An Analysis of Five North American Cities', Working Paper, pp. 0-25. Available at: http://innovativemobility.org/wpcontent/uploads/2016/07/Impactsofcar2go_FiveCities_2016.pdf.

Martin, E., Shaheen, S. and Lidicker, J. (2010) Carsharing's Impact on Household Vehicle Holdings : Results from a North American Shared-use Vehicle Survey.

Morency, C., Trépanier, M. and Agard, B. (2011) 'Typology of carsharing members', in 90th Transportation Research Board.

Müller, J., Correia, G. and Bogenberger, K. (2017) 'An Explanatory Model Approach for the Spatial Distribution of Free-Floating Carsharing Bookings: A Case-Study of German Cities', Sustainability, 9(7), p. 1290. doi: 10.3390/su9071290.

Namazu, M. and Dowlatabadi, H. (2018) 'Vehicle ownership reduction: A comparison of one- 
way and two-way carsharing systems', Transport Policy. Elsevier Ltd, 64(November 2016), pp. 38-50. doi: 10.1016/j.tranpol.2017.11.001.

NHTS (2016) Main Study Retrieval Questionnaire.

Niels, T. and Bogenberger, K. (2017) 'Booking Behavior of Free-Floating Carsharing Users Empirical Analysis of Mobile Phone App and Booking Data Focusing on Battery Electric Vehicles', Transportation Research Record: Journal of the Transportation Research Board, 2650, pp. 123-132.

Office for National Statistics (2011a) Census 2011, "Population density".

Office for National Statistics (2011b) Census 2011, 'Household composition'.

Office for National Statistics (2011c) Census 2011, "Tenure-Household".

Schmöller, S. et al. (2015) 'Empirical analysis of free-floating carsharing usage: The Munich and Berlin case', Transportation Research Part C: Emerging Technologies, 56, pp. 34-51. doi: 10.1016/j.trc.2015.03.008.

Wang, X., MacKenzie, D. and Cui, Z. (2017) 'Complement or Competitor? Comparing car2go and Transit Travel Times, Prices, and Usage Patterns in Seattle', Transportation Research Record, 589(17). Available at: http://faculty.washington.edu/dwhm/wpcontent/uploads/2017/02/Wang-MacKenzie-Cui-17-06234.pdf. 


\section{Tables}

Table 1: Previous studies of frequency of carsharing usage

\begin{tabular}{lll}
\hline Citation & Data source & Methodology \\
\hline $\begin{array}{l}\text { (Müller, Correia and } \\
\text { Bogenberger, 2017) }\end{array}$ & $\begin{array}{l}\text { DriveNow Berlin (free- } \\
\text { floating); } \\
\text { Census }\end{array}$ & Negative binomial model \\
\hline & & \\
& $\begin{array}{l}\text { A free-floating carsharing } \\
\text { operator in Basel, }\end{array}$ & \\
& Switzerland; & Linear Cliff-and-Ord-type \\
(Becker, Ciari and & Canton of Basel-Stadt; & SARAR model; \\
Axhausen, 2017) & Canton of Basel-Land & \\
&
\end{tabular}

Notable findings

Free-floating carsharing has higher demand in higher-

income areas

Free-floating carsharing mainly used for discretionary trips;

Station-based one-way

carsharing depends more

strongly on public transport,

whereas free-floating

carsharing serves to "fill in

gaps" in the public transport network

Many low-frequency members;

Frequency and travel distance are highly correlated;

(Morency, Trépanier and

Communauto (round-trip)

k-mean cluster analysis

Members found to have similar recurring weekly patterns approximately two thirds of the time

Accessibility to the service an important determinant of membership growth and frequency of usage; Members make less than 30 trips per year on average, and more than half travel less than $40 \mathrm{~km}$ by carsharing;

Most trips for non-work

(Costain, Ardron and Habib, AutoShare Toronto 2012) (round-trip) Census;
Binary logit model;

Log-logistic hazard model Negative binomial model; Multinomial logit model; Multivariant regression purpose;

Most trips short-distance and during off-peak periods; usage is higher on weekends; Low pricing and high perceived savings lead to longer membership duration; Carsharing members generally environmentally conscious and willing to pay for carbon offset; Membership duration and frequency of usage are lower in dense neighbourhoods

Likelihood of unsubscribing in any given period is negatively linked with increasing membership duration; Increasing number of cars at stations does not influence the decision of remaining members, however does increase frequency of usage; Membership duration increases with zonal population but decreases with zonal household car ownership Size of carsharing station (\# of vehicles) has a large impact on both availability and usage of the carsharing service; Seasonal impact on both availability and usage; Carsharing stations close to metro stations have low availability but high usage; Users prefer newer cars 
(Kang, Hwang and Park, 2016)

GreenCar Seoul (roundtrip)

Linear regression

(Hui, Ding, Qian, et al., 2017)

Chefenxiang Hangzhou (round-trip)

Clustering LARge

Applications (CLARA)

Carsharing demand is high in business areas and areas with many young residents (20s and 30 s), high car ownership and low underground train access

5 clusters of users are identified, and carsharing is heavily used for commuting in 4 of the segments;

Having "open-minded" residents is important; Central areas and areas with "good availability of parking lots" have higher demand Long-term users classified into 4 clusters by the frequency of usage, weekly usage pattern, and time of pick-up and returning the car

Demand highly concentrated in small number of temporal peaks and spatial "hot spots";

A free-floating carsharing operator in Berlin and Munich, Germany; Infas k-mean;

linear regression Weather significantly impacts demand;

Density of businesses and rent price ratio both positively impact demand 
Table 2: Parameters of regression models in the literature of carsharing usage frequency

\begin{tabular}{|c|c|c|c|c|c|c|c|c|c|c|}
\hline Citation & $\begin{array}{l}\text { Gender } \\
\text { (Male) }\end{array}$ & Income & $\begin{array}{l}\text { Populatio } \\
\text { n density }\end{array}$ & Age & $\begin{array}{c}\text { Car } \\
\text { ownersh } \\
\text { ip }\end{array}$ & $\begin{array}{l}\text { Tenure } \\
\text { (rent) }\end{array}$ & $\begin{array}{l}\text { Household } \\
\text { with } \\
\text { children }\end{array}$ & $\begin{array}{l}\text { Density of } \\
\text { businesses }\end{array}$ & $\begin{array}{l}\text { Public } \\
\text { transport } \\
\text { access }\end{array}$ & $\begin{array}{c}\text { Carsharing } \\
\text { member } \\
\text { density }\end{array}$ \\
\hline $\begin{array}{l}\text { (Müller, Correia and Bogenberger, 2017) (free- } \\
\text { floating) }\end{array}$ & & & Negative ${ }^{\star *}$ & $\begin{array}{l}\text { Positive }^{*} \text { for } \\
\text { presence of } \\
\text { children (up to } \\
\text { age 14) and } \\
\text { adults aged 25- } \\
49 ; \text { negative for } \\
\text { other age } \\
\text { bands }\end{array}$ & Negative $^{*}$ & & & Positive $^{*}$ & & \\
\hline $\begin{array}{l}\text { (Becker, Ciari and Axhausen, 2017) (free- } \\
\text { floating) }\end{array}$ & & & Positive $^{* *}$ & & Positive & & & Negative $^{* * *}$ & Positive & Positive $^{* * *}$ \\
\hline (Costain, Ardron and Habib, 2012) (round-trip) & $\underset{* *}{N e g a t i v e}{ }^{*}$ & Negative $_{* *}^{*}$ & Negative $^{\star *}$ & & & & & & & \\
\hline (Habib et al., 2012) (round-trip) & Positive $^{* * *}$ & & & Negative ${ }^{* * *}$ & & & & & & \\
\hline (de Lorimier and El-Geneidy, 2013) (round-trip) & & Negative $^{*}$ & & & & & & Negative & Positive $^{*}$ & Positive \\
\hline (Kang, Hwang and Park, 2016) (round-trip) & & & & Negative $e^{* * *}$ & Positive & & & & Negative ${ }^{* * *}$ & \\
\hline (Schmöller et al., 2015) (free-floating) & & & & $\begin{array}{l}\text { Negative } \\
\text { (significance } \\
\text { not stated) }\end{array}$ & & $\begin{array}{l}\text { Positive } \\
\text { (significance } \\
\text { not stated) }\end{array}$ & $\begin{array}{l}\text { Positive } \\
\text { (significance } \\
\text { not stated) }\end{array}$ & $\begin{array}{l}\text { Positive } \\
\text { (significance } \\
\text { not stated) }\end{array}$ & & \\
\hline Our result (round-trip) & & Positive & Positive & & Negative $^{*}$ & Positive & Negative & & & \\
\hline
\end{tabular}

Note: ${ }^{*},{ }^{* *}$, and ${ }^{* * *}$ denote $p<0.10, p<0.05$, and $p<0.01$, respectively. 
Table 3: Previous studies of carsharing subscription impacts on vehicle miles travelled

\begin{tabular}{|c|c|c|c|}
\hline Citation & Data source & Methodology & Notable findings \\
\hline $\begin{array}{l}\text { (Martin and } \\
\text { Shaheen, 2011a) }\end{array}$ & $\begin{array}{l}\text { Survey of members of } \\
11 \text { carsharing } \\
\text { services in North } \\
\text { America }\end{array}$ & Descriptive & $\begin{array}{l}\text { Members decrease VKT/year by } 27 \% \text {; } \\
\text { Mean observed impact of carsharing on greenhouse gas } \\
\text { emission is }-0.58 \text { ton/year; full impact is }-0.84 \text { ton/year }\end{array}$ \\
\hline $\begin{array}{l}\text { (Costain, Ardron } \\
\text { and Habib, 2012) }\end{array}$ & $\begin{array}{l}\text { AutoShare Toronto } \\
\text { (round-trip) } \\
\text { Census; }\end{array}$ & $\begin{array}{l}\text { Binary logit } \\
\text { model; } \\
\text { Log-logistic } \\
\text { hazard model; } \\
\text { Negative } \\
\text { binomial model; } \\
\text { Multinomial logit } \\
\text { model; } \\
\text { Multivariant } \\
\text { regression }\end{array}$ & See row describing this study in Table 1 \\
\hline (Cervero, 2003) & $\begin{array}{l}\text { Survey of City } \\
\text { Carshare San } \\
\text { Francisco Bay Area } \\
\text { (round-trip) members }\end{array}$ & $\begin{array}{l}\text { Binomial logit } \\
\text { model; }\end{array}$ & $\begin{array}{l}\text { VMT of carsharing members decreases less than a } \\
\text { control group }\end{array}$ \\
\hline $\begin{array}{l}\text { (Cervero and } \\
\text { Tsai, 2003) }\end{array}$ & $\begin{array}{l}\text { Survey of City } \\
\text { Carshare San } \\
\text { Francisco Bay Area } \\
\text { (round-trip) members }\end{array}$ & $\begin{array}{l}\text { Binomial logit } \\
\text { model; } \\
\text { Multiple } \\
\text { regression }\end{array}$ & $\begin{array}{l}\text { VMT of carsharing members decreases more than non- } \\
\text { members ( } 0.09 \text { average decrease for members and } 6.37 \\
\text { increase for non-members); } \\
73.3 \% \text { of members shed or opt not to purchase a vehicle, } \\
\text { compared to } 42.9 \% \text { of non-members }\end{array}$ \\
\hline $\begin{array}{l}\text { (Cervero, Golub } \\
\text { and Nee, 2007) }\end{array}$ & $\begin{array}{l}\text { Survey of City } \\
\text { Carshare San } \\
\text { Francisco Bay Area } \\
\text { (round-trip) members }\end{array}$ & $\begin{array}{l}\text { Multinomial logit } \\
\text { model; } \\
\text { Binomial logit } \\
\text { model; } \\
\text { Ordinal logit } \\
\text { model; } \\
\text { Multiple } \\
\text { regression }\end{array}$ & $\begin{array}{l}\text { Members' mean mode-adjusted VMT decreases by } 67 \% \\
\text { over the } 4 \text { years; } \\
\text { Users } 12 \% \text { more likely to shed a private vehicle than } \\
\text { non-members; } \\
\text { Complementarity between public transport and } \\
\text { carsharing }\end{array}$ \\
\hline $\begin{array}{l}\text { (Martin and } \\
\text { Shaheen, 2016) }\end{array}$ & $\begin{array}{l}\text { Survey of Car2go } \\
\text { (free-floating) } \\
\text { members in } 5 \text { cities in } \\
\text { North America }\end{array}$ & Descriptive & $\begin{array}{l}\text { Most members walk more frequently and use public } \\
\text { transport and taxi less frequently; } \\
\text { FFCS affects a small number of users' decision to shed } \\
\text { or postpone vehicle purchasing, but net impact on car } \\
\text { ownership is a decrease; } \\
\text { The minority who sell/discard vehicles contribute most to } \\
\text { VMT reduction, and net VMT reduction of car2go } \\
\text { members }\end{array}$ \\
\hline $\begin{array}{l}\text { (Chen and } \\
\text { Kockelman, 2015) }\end{array}$ & $\begin{array}{l}\text { Summary of } \\
\text { published literature }\end{array}$ & & $\begin{array}{l}\text { "Potential carsharing users" reduce energy use and } \\
\text { greenhouse gas emission } 48 \% \text { upon joining carsharing. } \\
\text { Reduction would be } 5 \% \text { of household VMT if scaled up to } \\
\text { all US households; } \\
\text { VMT can be reduced by } 33 \% \text { to } 69 \% \text { if "potential users" } \\
\text { join carsharing }\end{array}$ \\
\hline
\end{tabular}


Table 4: Parameters of regression models in the literature of VMT change

Citation

(Costain, Ardron and Habib, 2012) (round-

Gender (Male) Income Population density Age Car ownership

Car decrease

Tenure (rent)

Household with children

trip)

(Cervero, Golub and

Nee, 2007) (round-trip)

Quadratic

with age

Negative

and age

squared

being

Our result

Positive

positive)

Note: ${ }^{*},{ }^{* *}$, and ${ }^{* * *}$ denote $p<0.10, p<0.05$, and $p<0.01$, respectively.

Negative

Positive

Positive 
Table 5: List of variables and descriptive statistics

\begin{tabular}{|c|c|c|c|}
\hline $\begin{array}{l}\text { Variable name (as appears in } \\
\text { subsequent tables) }\end{array}$ & Description & Mean & $\begin{array}{l}\text { Standard } \\
\text { deviation }\end{array}$ \\
\hline Frequency: Carsharing & Frequency of using carsharing, per year & 30.47 & 35.14 \\
\hline Impact on VMT & Vehicle miles travelled change after joining carsharing & -563.99 & $2,466.28$ \\
\hline Impact on VMT (trimmed) & $\begin{array}{l}\text { Vehicle miles travelled change after joining carsharing } \\
\text { (trimmed at }-5000 \text { and } 5000 \text { miles) }\end{array}$ & -368.39 & $1,473.89$ \\
\hline $\mathrm{HH}$ income & Zonal-average household annual income in GBP/10000 & $\begin{array}{l}£ 57,293 \\
\quad 046\end{array}$ & $\begin{array}{l}£ 18,173 \\
014\end{array}$ \\
\hline$\%$ of HHs with children & Zonal-fraction of household with children & 0.26 & 0.09 \\
\hline$\%$ of $\mathrm{HHs}$ that own residence & Zonal-fraction of household owning properties & 0.39 & 0.17 \\
\hline Population per hectare & Zonal population density & 127.49 & 65.54 \\
\hline \# years of membership & Number of years of membership (before 2016) & 3.02 & 3.16 \\
\hline Member of one-way carsharing & $\begin{array}{l}1 \text { if the respondent subscribes both round-trip and one- } \\
\text { way carsharing and } 0 \text { otherwise }\end{array}$ & 0.08 & 0.27 \\
\hline Purpose: Business & $\begin{array}{l}1 \text { if the purpose of the last carsharing trip is business and } \\
0 \text { otherwise }\end{array}$ & 0.08 & 0.27 \\
\hline Purpose: Education & $\begin{array}{l}1 \text { if the purpose of the last carsharing trip is education } \\
\text { and } 0 \text { otherwise }\end{array}$ & 0.02 & 0.15 \\
\hline Purpose: Shopping & $\begin{array}{l}1 \text { if the purpose of the last carsharing trip is shopping and } \\
0 \text { otherwise }\end{array}$ & 0.27 & 0.45 \\
\hline Purpose: Pers. Bus & $\begin{array}{l}1 \text { if the purpose of the last carsharing trip is personal } \\
\text { business and } 0 \text { otherwise }\end{array}$ & 0.35 & 0.48 \\
\hline Purpose: Visit & $\begin{array}{l}1 \text { if the purpose of the last carsharing trip is visit } \\
\text { friends/family and } 0 \text { otherwise }\end{array}$ & 0.02 & 0.15 \\
\hline Purpose: Leisure & $\begin{array}{l}1 \text { if the purpose of the last carsharing trip is leisure and } 0 \\
\text { otherwise }\end{array}$ & 0.23 & 0.42 \\
\hline Purpose: Commuting & $\begin{array}{l}\text { The purpose of the last carsharing trip was commute } \\
\text { (binary) }\end{array}$ & 0.03 & 0.16 \\
\hline \# adult (age 16+) pax & $\begin{array}{l}\text { The number of adults travelled with in the last carsharing } \\
\text { trip }\end{array}$ & 1.19 & 0.89 \\
\hline \# child (under age 16) pax & $\begin{array}{l}\text { The number of children travelled with in the last } \\
\text { carsharing trip }\end{array}$ & 0.29 & 0.66 \\
\hline \multirow[t]{2}{*}{ Luggage } & 1 if the respondent carries luggage in the last trip (binary) & 0.49 & 0.50 \\
\hline & $\begin{array}{l}\text { If carsharing was not available in your last carsharing } \\
\text { trip... }\end{array}$ & 0.30 & 0.46 \\
\hline Journey cancelled & $\begin{array}{l}\ldots 1 \text { if the respondent would not make the trip and } 0 \\
\text { otherwise }\end{array}$ & 0.09 & 0.28 \\
\hline Journey by walk/bicycle & $\begin{array}{l}\ldots 1 \text { if the respondent would choose to walk or bike and } 0 \\
\text { otherwise }\end{array}$ & 0.40 & 0.49 \\
\hline Journey by PT & $\begin{array}{l}\ldots 1 \text { if the respondent would take public transport (bus, } \\
\text { underground train or train) and } 0 \text { otherwise }\end{array}$ & 0.33 & 0.47 \\
\hline Journey by taxi & $\begin{array}{l}\ldots 1 \text { if the respondent would take taxi or on-demand taxi } \\
\text { and } 0 \text { otherwise }\end{array}$ & 0.23 & 0.42 \\
\hline Journey by car & $\begin{array}{l}\ldots 1 \text { if the respondent would choose car and } 0 \text { otherwise } \\
1 \text { if the reason of using carsharing in the last carsharing }\end{array}$ & 0.50 & 0.50 \\
\hline PT service poor & $\begin{array}{l}\text { trip is because of the inconvenience of public transport } \\
\text { and } 0 \text { otherwise }\end{array}$ & 157.41 & 79.70 \\
\hline Frequency: Walk/bicycle & Frequency of walk or bike per year & 257.19 & 128.80 \\
\hline Frequency: PT & $\begin{array}{l}\text { Frequency of taking public transport (bus, underground } \\
\text { train or train) per year }\end{array}$ & 51.77 & 65.31 \\
\hline $\begin{array}{l}\text { Frequency: Car } \\
\text { Frequency: Taxi }\end{array}$ & $\begin{array}{l}\text { Frequency of using car per year } \\
\text { Frequency of using taxi or on-demand taxi per year }\end{array}$ & $\begin{array}{c}42.56 \\
0.32\end{array}$ & $\begin{array}{c}48.77 \\
0.47\end{array}$ \\
\hline Car ownership decrease & $\begin{array}{l}1 \text { if the car ownership was decreased after joining } \\
\text { carsharing and } 0 \text { otherwise }\end{array}$ & 0.23 & 0.42 \\
\hline Own car now & $\begin{array}{l}1 \text { if the respondent still has a car now and } 0 \text { otherwise } \\
\text { Level of satisfaction with the proximity of carsharing }\end{array}$ & 4.08 & 1.13 \\
\hline Satisfaction: Proximity & $\begin{array}{l}\text { vehicles to one's residence ( } 5 \text { is the highest and } 1 \text { is the } \\
\text { lowest) }\end{array}$ & 3.90 & 1.01 \\
\hline Satisfaction: Availability & $\begin{array}{l}\text { Level of satisfaction with the availability (temporal) of } \\
\text { carsharing vehicles ( } 5 \text { is the highest and } 1 \text { is the lowest) }\end{array}$ & 4.14 & 0.94 \\
\hline Satisfaction: Quality/Condition & $\begin{array}{l}\text { Level of satisfaction with the quality and condition of } \\
\text { carsharing vehicles ( } 5 \text { is the highest and } 1 \text { is the lowest) }\end{array}$ & 0.54 & 0.50 \\
\hline
\end{tabular}


Table 6: Regression results of frequency of carsharing usage per year

\begin{tabular}{|c|c|c|c|c|}
\hline & \multicolumn{2}{|c|}{ Model \#1a (full model) } & \multicolumn{2}{|c|}{$\begin{array}{l}\text { Model \#1b (variables with } \mathrm{p}>0.15 \\
\text { excluded) }\end{array}$} \\
\hline & Coefficient & $p$-value & Coefficient & p-value \\
\hline Intercept & $35.694^{\star \star \star}$ & $<0.001$ & $34.198^{* * *}$ & $<0.001$ \\
\hline HH income (£/year) & 4.920 & 0.439 & - & - \\
\hline$\%$ of adults with degree & $-25.751^{* * *}$ & 0.010 & $-10.125^{*}$ & 0.056 \\
\hline$\%$ of HHs with children & -19.592 & 0.147 & - & - \\
\hline$\%$ of $\mathrm{HHs}$ that own residence & -3.633 & 0.565 & - & - \\
\hline Population per hectare & 0.006 & 0.640 & - & - \\
\hline \# years of membership & $-0.695^{* * *}$ & 0.007 & $-0.734^{* * *}$ & 0.002 \\
\hline Member of one-way carsharing & $11.600^{* * *}$ & $<0.001$ & $11.029^{* * *}$ & $<0.001$ \\
\hline Purpose: Business & $18.366^{\star \star \star}$ & $<0.001$ & $14.678^{* * \star}$ & $<0.001$ \\
\hline Purpose: Education & $22.316^{\star \star *}$ & $<0.001$ & $27.228^{* * *}$ & $<0.001$ \\
\hline Purpose: Shopping & $11.350^{* * *}$ & $<0.001$ & $10.864^{* * *}$ & $<0.001$ \\
\hline Purpose: Pers. Bus & $5.687^{* * *}$ & 0.002 & $4.892^{* * *}$ & 0.004 \\
\hline Purpose: Visit Friends/Relatives & 2.648 & 0.608 & - & - \\
\hline Purpose: Leisure & $4.949^{* *}$ & 0.013 & $4.062^{* *}$ & 0.027 \\
\hline Purpose: Commuting & $33.906^{\star \star \star}$ & $<0.001$ & $30.703^{* * \star}$ & $<0.001$ \\
\hline \# adult (age $16+$ ) pax & $1.673^{*}$ & 0.063 & $1.594^{*}$ & 0.059 \\
\hline \# child (under age 16) pax & $2.079^{*}$ & 0.082 & $2.163^{*}$ & 0.054 \\
\hline Luggage & $-9.241^{\star \star *}$ & $<0.001$ & $-8.710^{* * *}$ & $<0.001$ \\
\hline Journey cancelled & -0.922 & 0.679 & & - \\
\hline Journey by walk/bicycle & 4.592 & 0.110 & $4.632^{*}$ & 0.080 \\
\hline Journey by PT & -1.285 & 0.513 & - & - \\
\hline Journey by taxi & 0.640 & 0.738 & - & - \\
\hline Journey by car & -1.447 & 0.501 & - & - \\
\hline PT service poor & 0.200 & 0.901 & - & - \\
\hline Frequency: Walk/bicycle & $-0.026^{* *}$ & 0.011 & $-0.025^{* * *}$ & 0.008 \\
\hline Frequency: PT & 0.009 & 0.173 & - & - \\
\hline Frequency: Car & $0.031^{*}$ & 0.052 & - & - \\
\hline Frequency: Taxi & $0.101^{* t * t}$ & $<0.001$ & $0.101^{n+* *}$ & $<0.001$ \\
\hline Car ownership decrease & $3.868^{* *}$ & 0.027 & $3.878^{* *}$ & 0.017 \\
\hline Own car now & $-5.632^{* *}$ & 0.019 & $-4.131^{* *}$ & 0.026 \\
\hline Satisfaction: Proximity & 1.152 & 0.176 & - & - \\
\hline Satisfaction: Availability & 0.783 & 0.406 & - & - \\
\hline Satisfaction: Quality/Condition & $-1.737^{*}$ & 0.055 & -1.248 & 0.115 \\
\hline
\end{tabular}

Note: ${ }^{*},{ }^{* *}$, and ${ }^{* * *}$ denote $p<0.10, p<0.05$, and $p<0.01$, respectively. 
Table 7: Regression results of VMT change ('capped' at $-5,000$ and $+5,000$ miles/yr)

\begin{tabular}{|c|c|c|c|c|}
\hline & \multicolumn{2}{|c|}{ Model \#2a (full model) } & \multicolumn{2}{|c|}{$\begin{array}{l}\text { Model \#2b (variables with } p>0.15 \\
\text { excluded) }\end{array}$} \\
\hline & Coefficient & $\mathrm{p}$-value & Coefficient & $\mathrm{p}$-value \\
\hline Intercept & -256.422 & 0.549 & $326.515^{* *}$ & 0.020 \\
\hline HH income (£/year) & 374.224 & 0.223 & - & - \\
\hline$\%$ of adults with degree & 497.472 & 0.329 & - & - \\
\hline$\%$ of HHs with children & 672.116 & 0.322 & - & - \\
\hline$\%$ of $\mathrm{HHs}$ that own residence & -514.494 & 0.109 & - & - \\
\hline Population per hectare & 0.117 & 0.860 & - & - \\
\hline \# years of membership & 0.070 & 0.996 & - & - \\
\hline Member of one-way carsharing & $-406.442^{* * *}$ & 0.006 & $-336.256^{* * *}$ & 0.006 \\
\hline Used carsharing last month & -74.061 & 0.389 & - & - \\
\hline Purpose: Business & -91.178 & 0.531 & - & - \\
\hline Purpose: Education & -259.147 & 0.372 & - & - \\
\hline Purpose: Shopping & -45.683 & 0.632 & - & - \\
\hline Purpose: Pers. Bus & -7.045 & 0.938 & - & - \\
\hline Purpose: Visit Friends/Relatives & -416.500 & 0.109 & $-539.736^{* *}$ & 0.021 \\
\hline Purpose: Leisure & 110.731 & 0.264 & - & - \\
\hline Purpose: Commuting & -73.412 & 0.792 & - & - \\
\hline \# adult (age $16+$ ) pax & -21.834 & 0.632 & - & - \\
\hline \# child (under age 16) pax & -16.481 & 0.783 & - & - \\
\hline Luggage & $180.353^{* *}$ & 0.037 & $132.669^{* *}$ & 0.048 \\
\hline Journey cancelled & 144.329 & 0.202 & - & - \\
\hline Journey by walk/bicycle & -14.914 & 0.918 & - & - \\
\hline Journey by PT & $211.723^{* *}$ & 0.031 & - & - \\
\hline Journey by taxi & 49.981 & 0.598 & - & - \\
\hline Journey by car & 21.049 & 0.845 & - & - \\
\hline PT service poor & -50.544 & 0.525 & - & - \\
\hline Frequency: Carsharing & -0.554 & 0.698 & - & - \\
\hline Frequency: Walk/bicycle & 0.309 & 0.532 & - & - \\
\hline Frequency: PT & -0.062 & 0.843 & - & - \\
\hline Frequency: Car & -0.020 & 0.979 & - & - \\
\hline Frequency: Taxi & -1.855 & 0.046 & $-1.305^{*}$ & 0.067 \\
\hline Car ownership decrease & $-1296.944^{* * *}$ & $<0.001$ & $-1,285.514^{\star \star \star}$ & $<0.001$ \\
\hline Own car now & -3.284 & 0.978 & - & - \\
\hline Satisfaction: Proximity & $-101.874^{* *}$ & 0.015 & $-65.144^{\star *}$ & 0.033 \\
\hline Satisfaction: Availability & 4.739 & 0.918 & - & - \\
\hline Satisfaction: Quality/Condition & 44.592 & 0.313 & & \\
\hline
\end{tabular}

Note: ${ }^{*},{ }^{* *}$, and ${ }^{* * *}$ denote $p<0.10, p<0.05$, and $p<0.01$, respectively 
Page 28 